\title{
LIMONESE CREOLE PROVERBS AND SAYINGS
}

\author{
Anita Herzfeld \\ Franklin Perry
}

\begin{abstract}
The puropose of this study is to provide an analysis of proverbs and sayings in the Cost

Rica English Creole in the context of the cultural tradition of black Costa Ricans.
\end{abstract}

\section{Introduction}

Oral narratives, song performances, riddles, rhymes, and proverbs have traditionally constituted primary means of community entertainment in the folk cultures of the West African slaves transplanted to the Caribbean. These verbal expressions persist in the contemporary life of older West Indians as one of the many links between their basic African heritage and their newly-evolved Caribbean identity. Following this folk tradition, the Limonese Creole speakers of Port Limon, Costa Rica, a black minority of mainly Jamaican descent, delight in the use of language as a creative act in itself and they engage in all the oral art forms mentioned.

Within that wide context, this paper will deal with proverbs. In the colloquial experience of Limonese Creole speakers (from here on LC), these nuggets of popular wisdom, couched in the form of succint sayings, are as much a focal point of conversational exchanges, arguments, or rhetorical speech as are their Anancy stories. ${ }^{1}$ Proverbs cover a broad area of every day Limonese life, but they are especially used in three distinct ways: 1. as didactic tools in the rearing of children; 2 . among adults, as cutting social weapons, and 3. as encapsulating codas of oral narratives. Even though they are more commonly uttered by older generations of speakers, the young are constantly exposed to them. As a result, they internalize these proverbs; their knowledge is subconsciously stored as it were, for use at a later time, when they themselves become older and in turn employ them to express their own experience succintly2. 
The data on Limonese proverb performances used in this paper were elicited from different sources during a long span of time. The first corpus consists of conversations on a wide range of subjects in which some proverbs were interjected into ongoing discourse; the second consists of a set of proverbs obtained by eliciting both proverbs and short explanations regarding the range of situations in which they might be utilized and the range of meaning they might convey. Most of them were used in conversations that Franklin Perry held throughout his life with his late mother and some other older friends ${ }^{3}$, as well as in his informal chats with Anita Herzfeld since 1973. It is hoped that discerning the broader outlines of these particular speech events will provide some insight into the study of this genre of human communication.

\section{Goals}

Since all of us have encountered proverbs in conversations, we are familiar with them to such an extent that until recently, it was believed that,

The definition of a proverb is too difficult to repay the undertaking... An incommunicable quality tells us that this sentence is proverbial and that is not. (Taylor 1931: 3)

This intimate knowledge has led to using a priori and intuitive criteria in the identification and analysis of proverbs. Consequently, most studies have failed to distinguish this genre from semantically or functionally similar forms. In an attempt to overcome some of the pitfalls encountered by previous research, the brief first part of this paper will deal with the usage and the form of the proverb text. Although it seems to aid in the differentiation of proverbs from unmarked or ordinary use of language, context features have not received critical attention. In that sense, Briggs states that "the rhetorical force of proverb performances emerges from a subtle and complex use of the pragmatic functions of language." (Briggs 1985: 794). The second part of the paper will be devoted to the examination of a variety of proverbs, because ultimately such patterns may help clarify the organization of global knowledge structures.

\section{Primary proverb usages}

The obvious first step appears to be the need to provide some generalizations about the features all proverbs have in common, which may be amenable to analysis. All examples of the genre are alike in that they are sententious, witty remarks which embody wisdom, and they are used to control delicate but important social situations. Moreover, these terse messages express multiple meanings through different stylistic and semantic devices. The following usages may be listed for $\mathrm{LC}^{4}$ (examples that illustrate usages are drawn from the list of LC proverbs which appears in the second part of the paper): 
3.1. Proverbs that use associations with negative sanctions, although they are not necessarily overtly stated in the proverb itself

21. /riva kom down tuwod mowt stop/

"The river comes down, the toad mouth stops."

When the river overflows, toads stop calling the rain.

If you are looking for trouble, you will stop fooling around when it happens.

3.2. Proverbs that use puns, which are understood by certain groups

7. /kaal miy a daag bot dwon kaal miy tom pus/

"Call me a dog but don't call me a pussy cat."

$\operatorname{dog}=$ bitch $=$ whore; puss $=$ cat $=$ thief

Call me a whore, but don't call me a thief.

3.3. Proverbs which present challenges for verbal dueling and set the scene for other verbal art forms or games

42. /a wanda we jangkro dida duw bifo jakas ded/

"I wonder what John Crow (the vulture) did

(for food) before the jackass died."

Usually said to a man who suddenly

displays wealth which he cannot account for.

3.4. Proverbs that are said as jokes, but which even superficially aim at rectifying deviant behavior

6. /plye wid popiy, popiy lik yu mowt/

"If you play with (a) puppy, (the) puppy will lick your mouth."

Avoid familiarity with children or disrespectful people.

Cf. SE. "Familiarity breeds contempt."

\subsection{Proverbs which abuse someone subtly}

32. /a wislin wuman an krowin hen abomineyshen tu de laad/

"A whistling woman and a crowing hen are abomination to the Lord."

A woman who acts like a man ('wears the pants' in a household) is despicable (in God's eyes).

3.6. Proverbs which dwell on abstract principles, such as

34. /fala fashen monkiy olwiyz luwz im tyel/

"A monkey that follows the fashion always loses its tail."

One must be true to one's own identity. 


\section{Proverb form}

As to form, LC proverbs can be grouped as follows:

\subsection{A phrase (sentence fragment), such as}

1. Jtuw moch daag fi de syem bwon/

"Too many dogs for the same bone."

Cf. SE. "Too many cooks spoil the broth."

\subsection{A couplet, stated in parallel syntax}

33. /de haya monkiy klaym, de mo im ekspwoz im tyel/

"Thie higher the monkey climbs, the more it exposes its tail."

The higher a person climbs (socially), the more he/she will be scrutinized.

\subsection{A couplet, using repetition in sound}

125. /avi, avi, avi na wanti; wanti, wanti, wanti kyaan get it/

"Have it, have it, have it, does not want it; want

it, want it, want it, can't get it."

Who owns it does not want it; who wants it cannot get it.

People do not appreciate what they have.

Although not apparent in the data collected, it is very likely that some further classification could be made as to the settings of proverb usage: those that can be used by everyone, those that are not reciprocal -only adults may say them to children and not viceversa, and those that are reserved for members of certain groups depending on age and sex factors. Further research will be necessary to clarify this point.

On the other hand, note that even if we (1) summarized all the diverse circumstances of LC proverbs usage in a table (even more complete than the usages listed above), (2) made traditional functional statements about what proverbs do (i.e. summarize a situation, pass judgment, or recommend a course of action), or (3) attempted to analyze their superficial linguistic features, we would not produce a revealing analysis of what makes proverbs a different genre. It is precisely the very similarity of style, language, and syntax to ordinary speech which gives the genre the ambiguous quality it requires and which defies a different analysis from ordinary syntactic structures. ${ }^{5}$ However, as a result of focussing attention on the text and context of the proverbs, a few new general observations may be made based on the sample classified above.

Our field experience indicates that a legitimate analysis of the structure and meaning of proverb performance requires supplemental information obtained by scrutinizing the transcripts of actual occurrences, and by analyzing the discourse in which it is embedded. In that sense, 
Briggs claims that, "research on the social context of proverb performance has demonstrated the importance of contextual information in discerning the meaning of proverbs." (Briggs 1975: 794).

Briggs lists eight features which he considers indispensable to clarify this subtle and complex use of the pragmatic function of language. Following that line of thought, the proverbs listed below could conceivably be analyzed against the grid of those eight features. Future research in this area could result in productive insights about the context in which proverbs appear and could illuminate their meaning and usage.

TABLE 1

Summary of features and their characteristics

\begin{tabular}{llcc}
\hline & FEATURE & OBLIGATORY/OPTIONAL & TEXTUAL/CONTEXTUAL \\
\hline 1. & Tying phrase & + & $\mathrm{C}$ \\
2. & Identity of owner & + & $\mathrm{T}$ \\
3. & Quotative & + & $\mathrm{T}$ \\
4. & Proverb text & - & $\mathrm{T}$ \\
5. & Special association & - & $\mathrm{T}$ \\
6. & General meaning/ & - & $\mathrm{T}$ \\
& hypothetical situation & + & $\mathrm{C}$ \\
7. & Relevance to context & $\mathrm{C}$ \\
8. & Validation & & \\
\hline
\end{tabular}

Excerpted and adapted from Briggs 1975.

1. The "tying phrase" refers to the element used in proverb performance to join preceding utterances in the discourse to what is to follow.

2. The "identity of owner" is the citation of a person with whom the proverb is associated.

3. The "quotative" is the element -usually one of a small set of verbs, such as "say"- which introduces the proverb text.

4. The "proverb text" is the element which is usually isolated for collection and analysis.

5. "Special association" refers to the provenance of the proverb or to any specific association it may have, known to the speaker. This feature is not always present.

6. The "general meaning" of the proverb is often made explicit in the course of the following discourse.

7. "Relevance to context" refers to the practical application of the proverb to the present situation.

8. Most proverbs end with a "Validation of the performance" to assert the validity of the proverb.

The analysis of the proverbs used by LC speakers could attempt to answer 'What does one need to know or assume in order to interpret the meaning of a proverb? What propositions and inferences enter into the ethnopsychology of LC proverbs?' 
The corpus that follows is not intended to be exhaustive. The proverbs selected are grouped together merely because they share a common bond in as much as they refer to the human experience. In spite of this commonality, they are listed in several sections simply for convenience: proverbs which allude to dogs, to other animals, to vegetation, and miscellanous people references.

\section{Limonese creole proverbs which allude to dogs}

1. /tuw moch daag fi de syem bwown/

"Too many dogs for the same bone."

Two people sharing something could result in dissension (the same as two dogs which fight over a bone).

There is only one of its sort available to many contenders;

i.e. The demand is greater than the offer.

2. /daag in de myenje/

"Dog in the manger."

A dog cannot eat hay, but it won't let the horses come close to eat it either.

Cf. S. "Ni pica la leña ni presta el hacha."

3. /yon daag dwon nwo layan/

"Young dogs don't know the lions".

An inexperienced dog (i.e. anyone who is inexperienced) does not know danger.

4. /tu av moniy a stwon daag/

"To have money to stone a dog."

Someone has so much money that he/she does not know what to do with it; i.e. he/she can throw it away (and "stone a dog").

5. /taym so 'aad til daag an al a luk wok/

"Times are so hard that even dogs and all (i.e. everybody) are looking for work."

Times are difficult, so much so that everyone is affected by them.

6. /plye wid popiy, popiy lik yu mowt/

"If you play with a puppy, the puppy will lick your mouth."

Cf. SE. "Familiarity breeds contempt."

Social distance must be kept. 
7. /kaal miy a daag, bot dwon kaal mi tom pus/

"Call me a dog, but do not call me a cat."

Call me a whore, but do not call me a thief.

(Here 'dog' is equivalent to 'bitch' (whore), while 'puss' is equivalent to 'thief.')

8. /pus an daag olweyz ina war/

"The cat and the dog are always at war."

The cat and the dog (i.e. people) are always fighting.

9. /daag av tuw yaad, im sliyp widowt sopa/

"A dog which has two homes, sleeps without supper."

A person who does not maintain a steady home, may lose more than he gains.

10. /daag nyam yuw sopa/

"The dog eats your supper."

Said to a person who should be on the alert, because he will

be in trouble or out of luck.

11. /if yuw lay down wid daag, yuw get op wid fliy/

"If you lie down with a dog, you get up with fleas."

You must be careful in choosing your friends. There is danger

in emulating undesirable habits of 'wrong' friends.

12. /der a meniy wyez fa hang a daag widowt puting string rown im nek/

"There are many ways to hang a dog, without putting a string around his neck."

One can seek revenge in many ways.

13. /de daag wa tek a bwon wil kariy wan/

"The dog that takes a bone will also carry one."

One who shares gossip, will also disclose secrets entrusted to him.

14. /griydiy chwok popiy/

"Greediness chokes the puppy."

Don't bite more than you can chew, because you might choke on

it. If you are too greedy, you might hurt yourself in the end.

\section{6. proverbs which allude to other animals}

15. /evriy jangkrow tink im pikniy wayt/

"Every John Crow (black vulture) thinks its children (offspring) white." 
All parents think their own children perfect.

Everyone praises his/her own doings.

16. /saafliy saafliy, tayga kech monkiy/

"Softly, softly, the tiger (stalks and) catches the monkey."

When you want to do somehting, don't talk about it, just do it quietly.

17. /wen kakrwoch mek dans im no imbayt fowl/

"When the cocroach gives a dance he does not invite fowl."

Do not ask your enemies to join you; i. e. do not ask for trouble. Avoid dangerous situations and those who can harm you.

18. /no chyenj blak daag fi monkiy/

"Do not change a black dog for monkey."

Do not change the devil for a witch.

19. /neva kaal aligyeta big mowt til yu don kras di riva/

"Never call the alligator 'big mouth' until you have crossed

(you are done crossing) the river."

Don't give up your chances until you have other alternatives.

Be respectful of the one who has the upper hand for as long as he has it.

Cf. SE. "Don't burn your bridges behind you."

Don't commit yourself to a course from which there is no retreat.

20. /taiga maaga bot im no sik/

"The tiger looks slim but he is not sick."

Do not judge a man by his looks, i.e. do not judge people by their appearance only.

21. Ino mak maaga kow, im a bul muma/

"Don't mock a thin cow, it is the mother of bulls."

Don't trust appearances, because they are deceiving.

Don't disregard the weak, because they might have a strong backing.

22. /de syem tin we swiyt naniy gwot ron im got/

"The same thing that sweetens the she-goat upsets her gut."

Whatever makes you happy can also make you sad or sick; i.e.

something might give you transitory pleasure, but can also

bring about negative consequences.

23. /riva kom down tuwod mowt stop/

"When the river comes down, the toad mouth stops."

When the river overflows, toads stop calling the rain.

You are looking for trouble, and when it happens you shut up. 
24. lif yuw no mash ans, yuw no fayn im gots/

"If you don't smash ants, you don't find their guts."

If you want to know what someone really feels, you must make

$\mathrm{him} / \mathrm{h}$ er angry; i.e. given time an individual will show

his/her true self, i.e. the true side of his personality.

25. /a gwot hed evriy dye iz beta dan a kow hed on sondiyz/

"A goat's head every day is better than a cow's head on Sunday."

Something you already own is better than something you might (or not) get.

Cf. SE "A bird in hand is worth two in the bush."

Cf. S. "Más vale pájaro en mano que cien volando."

26. /hog di aks im muma we mek im mowt so lan -'yuw a grwo mi chayl bambay, yuw wi siy'l

"A pig asked its mother what makes its mouth (snout) so long-

"when you grow up my child, by and by, you will see (find out)'."

You will learn when you mature.

With experience comes the understanding of situations.

27. /wen pus beliy ful, rata batiy bita/

"When the cat's belly (tummy) is full, the mouse's bottom is bitter (smells)."

When you have had too much, you find fault with what you like.

28. Ituw moch rat neva dig guwd wol/

"Too many rats never dig a good hole."

Cf. SE. "Too many cooks spoil the broth."

Too many participants involved in a project are sure to

spoil it, i.e. to produce disastrous results.

29. /a no onliy wan taym monkiy wa wayf/

"It's not only one time that monkey wants a wife."

Never burn your bridges before you cross them.

If a person is ungrateful once, assistance may not be

forthcoming when he needs it again.

30. /bed ov wan feda bot no flok tugeda/

"Birds of a feather do not flock together."

Although people may seem to have something in common, they do not necessarily gather together.

Although people mix and interact, it does not mean they belong together. 
31. /wen fowl meriy, 'ak tek dem chikin/

"When a fowl is happy, the hawk takes its chickens."

When someone becomes neglectfully happy, he/she runs the risk

of losing something important.

Sadness always follows happiness.

32. /tuw bul kyaan ruwl ina wan pen/

"Two bulls can't rule in one pen."

One cannot have more than one boss.

A disobedient child must either mend his ways or go away.

33. /yuw kyan liyd jakas tu de pan, bot yuw kyaan myek im drink/

"You can lead a jackass to the pond, but you can't make him drink."

You can convince someone of something, but you cannot make him act upon it.

34. /a wislin uman an a krowin 'en iz abamineyshan tu de laad/

"A whistling woman and a crowing hen is abomination to the Lord."

Women should not behave like men.

A woman who acts like a man ('wears the pants' in a household)

is despicable (in God's eyes).

35. /de haya monkiy klaym, a de mwo im ekspwoz im tyel/

"The higher a monkey climbs, the more he exposes his tail."

The higher you climb, the more you will be scrutinized.

Even though you may wish to hide your activities or

possessions, sooner or later they will be discovered.

36. /fala fashen monkiy olwiyz luwz im tyel/

"A monkey that follows the fashion always loses its tail."

One must be true to one's own identity, otherwise fake

behavior may have disastrous consequences.

37. /dakta bod a foniy bod/

"The humming bird is a funny bird."

The humming bird lives a long time, because it is hard to kill; thus he is a strange bird.

38. /kow neva nwo de yuws ev im tyel til im luwz it/

"The cow never knows the use of its tail until it loses it."

A person may lose his/her friend (or assistance) because of ingratitude.

One does not appreciate people one loves until they are gone;

one should show appreciation for friends, relatives. and resources while one has them. 
39. /fishaman neva se im fish tink/

"The fisherman never says that his fish stink."

One never says unkind things about one's family, or the articles one intends to sell.

40. /no mata ow ay jangkrow flay, im afi kom a grown fi nyam/

"No matter how high John Crow (a vulture) flies, it has to come to the ground to eat."

No matter how important one may become, one must maintain humility.

41. /siybriyz blwo pelikyan syem plyes im waan gow/

"The sea breeze blows the pelican to the same place it wants to go."

The pelican changes the direction of its flight with each shift of the wind (seabreeze).

When someone wants something badly, he/she obtains it under any pretext. People find excuses to justify their choices.

42. /wen fish kom fram riva batam tel yu aligeta hav beliyiek biliyv im/

"When the fish comes from the river bottom, and tells you that

the alligator has a stomach-ache, believe him."

You must listen to the voice of experience.

You can't disregard experience because knowledge is derived from it.

43. /syek a mowt, fish get kech/

"For the sake of its mouth the fish gets caught."

Keep your mouth shut.

Cf. SE. "The fish gets caught by its mouth."

Cf. S. "En boca cerrada no entran moscas."

"Por la boca muere el pez."

44. /a wanda we jangkro dida duw bifo jakaas ded/

"I wonder what the vulture did (for food) before the jackass died."

Usually refers to a man who suddenly displays wealth which he cannot account for.

Someone takes advantage of someone else's misfortune.

45. /no kos 'ag, a im mek 'am/

"Don't curse a hog, (from him they make ham) he is what ham is made of." Appearances are deceiving.

46. /wen yu kyaan kech kwakul, grab im shot/

"If you cannot catch a guaku (an elusive bird used in obeah), grab its shirt."

When you take vengeance settle for something smaller than 
the whole (that which offended you), i. e. if you cannot

take vengeance on the offender, you take it out on whoever is closest to the offender.

47. /syem nayf tik shiyp tik gwot/

"The same knife that sticks (butchers) the sheep sticks (butchers) the goat."

What is suitable for one is also good for the other.

Cf. "What is good for the goose is good for the gander,"

i.e. justice will be done in the end equally for all.

Everybody is vulnerable.

48. /chikin meriy, 'aak nyer at 'an/

"When the chickens are merry, hawks are near at hand."

Never let your guard down because misfortune might be near.

If someone is engaging in negative behavior, he/she will soon pay the price.

49. /wen fowl meriy, 'aak de nye/

"When the chickens are happy, the hawk is near."

When the victim is careless, the attacker is watching for the opportunity to jump against him/her.

50. /wen fowl meriy, 'aak tek dem chikin/

"When fowl is merry, hawks take their chickens."

If mother-hen becomes careless, the hawk will take its chickens.

51. /beg waata kyaan bwayl kow fut/

"Water begged (from a neighbor) can't boil (will not be

enough to boil something as hard as) a cow's foot."

When you get something from others, don't expect it to be

everything you need. A person who only depends on others will not make it in life.

52. /wen jangkrow no waan go a lwo im se briyz a blwo/

"When the vulture does not want to fly low, it says that the

wind is (blowing) too strongly."

When you don't want to do something, you find pretexts not to

do it. One usually blames others when unable to accomplish a goal.

53. /no byed 'ag/

"Don't bathe a hog."

Don't waste your efforts; don't expend time and energy on

efforts that are not worth while. 
54. /evriy bod sing swiyt tu imself/

"Every bird sings sweetly to himself."

You must put your maximum effort into your own concerns.

55. /wen pus ley heg an rat av biyk/

"When a cat lays eggs and a rat has a beak."

An event that will never occur.

Cf. to "When hell freezes over."

A promise not expected to be fulfilled.

56. /a no fe de waan a tong mek kow no tak/

"It is not for the lack of a tongue that the cow doesn't talk."

People may have a lot to say, but keep quiet out of prudence.

57. /yuw nwowz wol de wopen/

"Your nose hole is opening."

You are getting wiser; you are maturing. (The same as a cow whose nostrils expand as the animal grows.)

58. /yuw layk kow wa gii a pyel a milk an kik it wova/

"You are like a cow that gives a pale of milk and kicks it over."

You appear to be a kind person, but in reality you are using your 'kindness' to extract a benefit.

You did an excellent job, but ultimately you ruined it.

Cf. S. "Borrar con el codo lo que hizo con la mano."

59. /if yu lov de kow, yuw mos lov de kaaf/

"If you love the cow, you must love the calf."

If you want to succeed, you must also appreciate hard work.

If you love the mother, you must love the children too.

60. /krab waak tuw faa, im luwz im kla/

"When the crab walks too far, he loses its claws."

Don't exceed your limitations. Live in moderation.

61. /we jangkrow gada, kakis de de/

"Where the crows gather, there is a carcass."

When there is trouble, the usual troublemakers are there.

62. /donkiy se de wel no level/

"Donkeys say the world is not levelled."

People are aware of the world's inequities.

It can be used with sexual connotations in that respect. 
63. /evritin wa hapen ina siy, dem se iz shark/

"Everything that happens in the sea, they say is caused by the shark."

When an offense is committed, a disreputable person gets always blamed for it.

64. /wa yuw kan ekspek fram a 'ag bot a gran/

"What can you expect from a hog but a grunt?"

One should expect people to act in the way that is consistent with their status.

65. I'ag wash ina de fos wata im riych/

"The hog washes in the first water it reaches."

One should take advantage of the opportunities that he/she is

being offered, because they might never turn up again.

66. Ino bay pus ina bag/

"Don't buy a cat in the bag."

Don't purchase anything without seeing it.

67. /wen snyek bayt yuw, yuw siy lizar yuw ron/

"If a snake has bitten you, the sight of a lizard will make you run."

If you had had a bad experience, you will be leery of a similar occurrence.

Cf. SE. "Once bitten twice shy."

\section{Vegetation}

68. /bush av iyaz/

"Bush have ears."

If you don't wish something you know to be spread, keep it for youself.

69. /wan wan koko, full baskit/

"One by one, cocos fill the basket."

If you are frugal and save, you may accumulate some wealth;

i.e. large quantities are made up of small amounts.

70. /wan bay wan, de baskit ful/

"One by one, the basket is filled."

Little infractions may lead to greater ones.

71. /if a lik yuw, yuw klaym maka triy/

"If I hit you, you climb macca tree."

If I hit you, you will have to do what I am telling you.

If I hit you, you are likely to perform what would otherwise have seemed an impossible task. 
72. /mek mi yaz nyam gras/

"Let my ears eat grass."

You are talking too much, please be quiet!

73. /liyf drap ina wata, it rotin/

"When a leave is dropped into the water, it rots."

The effects of one's actions manifest themselves eventually.

Prior to engaging in any activity, be sure to measure the results of your actions, because sooner or later you will have to suffer the consequences.

74. /if a tomp yuw, yu fayn owt we wata waak gow ina pumkin beliy/ "If I hit you, you will find out how the water got inside a pumpkin." If I hit you, you will find out what might seem impossible to you; i.e. your punishment will be severe.

75. /giy laf wid piy suwp/

"Give laughter with (in exchange for) pea-soup."

Said about the person who engages in fun talk (i.e. gossip) to get a free meal for it.

\section{Miscellanoues proverbs which allude to people}

76. /if yu waan fi nwo yu fren from yu enemiy drink rom an lye down a rwod sayd/ "If you want to know your friend from your enemy, drink rum (get drunk) and lie down on the road side." (since everybody who goes by the road will see you, some people will help you while others will talk ill about you, thinking you are not listening). If you want to know who is on your side, test your friends by who will help you out in disgrace

77. /wan fuwl myek meniy/

"One fool makes many."

By imitating others, you can make mistakes.

Folly has its adherents.

78. /wen yuw put klwodz adwo, yuw hafi waach ryen/ "When you put clothes (to dry) outdoors, you have to watch for the rain." If a matter does not concern you, you won't care about it; but if you feel guilty, you will worry about it. 
79. /iy yuw no spred klwot owtsay, yuw no watch ryen/ "If you don't spread clothes outside, you don't watch for rain." If you are not in trouble, you don't worry about the police.

80. /ryen a faal, bot dotiy tof/

"Rain is falling, but the dirt (ground) is tough."

Even though you might have a lot of problems, you must stand up to them. Rain would seem to indicate affluence; however, in spite of it and since the ground is tough, poverty is everywhere. The situation is in principle changeable.

81. /we yuw di de we tonda a rwol?/

"Where were you when thunder was rolling?"

Where were you hiding when something important (or difficult) was happening?

82. /wash piypl pikniy beliy, bot no wash dem bak/

"Wash people's children's belly, but do not wash their back."

Don't be extremely kind with other people's children, be aware that they are not your own, because they will go away and you will remain alone.

Don't go too far in interacting with others.

Cf. S. "El que cuida perro ajeno, pierde el pan y pierde el perro."

83. /no evritin we gud fi iyt, gud fiy taak/

"not everything that is good to eat (for eating) is good for talking."

Be discrete, you must not say everything you hear or know.

Respect the privacy of the family.

84. /kowad man kiyp sown bwon/

"The coward man keeps his bones sound."

If a man is brave he will fight; if he is a coward he will run away and keep his bones sound.

A cowardly person doesn't face anything but survives; he/she is less adventuresome and hence will avoid danger. A brave person faces danger and dies for it.

Cf. S "Es mejor que digan que aquí corrió (por cobarde) y no que aquí murió (por valiente).

85. /saafliy riva ron diyp/

"Soft rivers run deep."

Appearances are deceiving; in spite of being quiet, an

individual may well be profound and thoughtful. 
Cf. SE. "Quiet waters run deep."

Cf. S. "De las aguas mansas líbrame, que de las turbulentas me libro yo."

86. /wan dye fiys an di ada famin/

"One day feast and the other famine."

You shouldn't eat everythin you have in one day because you

are likely to starve the next day.

You must save; don't use up all your resources.

87. /tuw prowd tu beg tuw oprayt tu tiyf/

"Too proud to beg too upright to steal."

Don't be too proud to ask for help. Poverty is not a shame.

88. /rak twon a riva batam no nwo 'at san/ or /no nwo son 'at'

"Rock stones at the bottom of the river don't know (are never exposed) to the hot sun."

Children don't know adults' problems, i.e. they are protected from reality; the rich don't know the discomforts of the poor and cannot empathize with them. Whoever hasn't experienced something, he/she doesn't quite understand the predicaments of others who suffer.

89. /huw fiyl it nwo it/

"He who feels it knows it."

He who has had experience, understands it.

90. /taym lange dan rwop/

"Time is longer than rope."

There is more time than life. You must be patient.

Given enough time, grievances will be redressed.

Cf. S. "Hay más tiempo que vida."

91. /if yu nwo yu av sach window no trwo stwon/

"If you know you have sash windows do not throw stones."

Do not criticize or slander others if you are vulnerable.

Cf. SE. "Those who live in glass houses shouldn't throw stones."

92. /if yuw nwo yu tyel bwon na strang, na swalow plom siyd/

"If you know that your tail bone is not strong, don't swallow plum seeds."

Don't get into things you cannot handle.

If you know your limitations, do not become involved in

issues you cannot cope with.

Cf. SE. "Don't bite more than you can chew." 
93. /no evritin we glita iz gwol/

"Not everything that glitters is gold."

Don't trust appearances.

94. /dopiy nwow huw fi fraytin a dak nayt/

"Ghosts know whom to frighten in a dark night."

The devil knows whom to frighten, i.e. people will take

advantage of the weak, those that are vulnerable and can be easily fooled.

95. /mama av, papa av, bot blesed iz de chayl we av im won/

"Mother has, father has, but blessed is the child that has his own."

It is better for a child to be independent.

96. /tuw pon wan iz meda/

"Two (people) (fighting) upon one is murder."

To take advantage of someone is foul play.

97. /krismas kom bot wans a yer/

"Christmas comes but once a year."

You can only get away with things once.

98. Ino everiy dye a krismas/

"Not every day is Christmas."

Life is not always filled with good times.

Cf. SE. "It is not Christmas every day."

99. /trobel na set op layk ryen/

"Trouble is not set up (doesn't come) like rain."

Trouble doesn't come announced; it is not like rain which

follows a storm. You cannot forecast trouble; you cannot plan ahead to face it.

Misfortune does not give signals of its coming, as the rain

does, but instead it comes unannounced. We must be prepared to cope with it.

100. /fuwl de taak, bot no fuwl de lisn/

"The fool is talking, but no fool is listening."

Although whoever is talking maybe a fool, the listener never thinks he is a fool too Read between lines. One is constantly interpreting what the interlocutor is saying, and ultimately, the listener assesses the speaker less kindly then he assesses himself.

101. /yuw neva siy smwok widawt faya/

"You never see smoke without fire."

There is always a reason for everything, i.e. a motive behind every action.

Cf. SE. "There is no smoke without fire." 
102. /mi afi tek bad tin mek laf/

"I have to take bad things and laugh at them."

One has to have a sense of humor.

You have to be able to put the best front, even if you are miserable.

Cf. S. "A mal tiempo buena cara."

103. /if yu beg yu naa get, if yu na beg yu naa want/

"If you beg you don't get, if you don't beg you don't want."

If someone doesn't want to give you something, he/she will

find excuses; i.e. you end up by not getting anything anyway.

104. /a bega from a bega iz a tiyf/

"A beggar from a beggar is a thief."

A beggar who begs from another beggar is taking advantage of

someone who has nothing.

105. /it tek tuw tu mek a kworil/

"It takes two to make a quarrel."

You can only have a quarrel if the two of you are willing to fight.

106. /wen wan na waan tuw dwon fayt/

"When one doesn't want [to fight] two don't fight."

You can provoke someone, but unless both want to fight, there will not be a quarrel.

Cf. SE. "It takes two to tango."

Some things can't be done just by yourself.

107. /lok biyt owbiya/

"Luck beats obeah."

Bad luck is even worse than a spell cast upon you.

108. /yuw set pikniy gwost pon yuw/

"You set children's ghosts upon you."

This is the worst that can happen to you.

109. /likl aks fal big triy/

"Little ax falls big trees."

One can destroy big things with little effort.

The powerful can be brought down by the weak.

110. /wyet kil man/

"Weight [or wait] kills man."

A load [or time] can destroy a person. 
111. lif yuw spit in de skay, it faal in yu fyes/

"If you spit on the sky, it falls on your face."

If you go against God, it will hurt you.

Whatever you do out of pride might act against you.

112. /wan finga paint pon de neks persin, far finga paint bak pon yuw/

"[If you] point a finger at someone, the forefinger will point back upon you."

Whatever you do unto others, will likely happen to you.

The person who accuses or distrusts others may deserve the greatest blame.

113. /tuw moch ov wan tin mek man gud fi notin/

"Too much of one thing makes man good for nothing."

Anything to excess is no good.

114. /devil olwez fayn wok fi giy aygl an fi duw/

"The devil always finds work to give idle hands."

Idleness brings about bad results.

115. /an aigl mayn iz de devil wokshop/

"An idle mind is the devil's workshop."

You can easily get into trouble when you don't have anything to do.

116. /wen man na a notin fi duw, im gow tel kow gud maanin/ or

/wen man na a notin fi duw, im giy laaf wid piy suwp/

"When man has nothing to do, he tells the cow good morning."

"When man has nothing to do, he laughs with the pea soup."

A person who doesn't have to strive for a livelihood does

absurd things (i.e. like greeting a cow or having fun with the pea soup).

117. /blak an wayt na tel lay/

"Black and white do not tell lies."

Whatever is written down stays.

118. /wen bad lok tek yu, pikni shot fit yuw/ or

/wen trobl tek yu, pikni frak fit yuw/

"When bad luck grabs you, a child's shirt fits you."

"When trouble assails you, a child's garment fits you."

When you have bad luck, you must accept it.

Cf. SE."A drowning man holds on to a straw."

When you go through difficult times, you must make do with your ill fortune.

You must lower your standards in adverse circumstances and your

resilience will pull you through. 
119. Ino kye ow lan de preya, it mosi av a eymen/

"No matter how long the prayer is, it must have an 'amen'."

Don't despair, problems will be solved in time. No harm will

last one hundred years. Time will solve a lot of problems.

Cf. SE."Every cloud has its silver lining."

Cf. S. "No hay mal que dure 100 años -ni cuerpo que lo resista."

120. /wan an mos wash di ada/

"One hand must wash the other."

We must learn to work together and share resources.

Cf. SE. "One hand washes the other."

121. /tuw moch pork fi di shilin/

"Too much pork for the shilling."

You are asking too much for what you are giving.

122. /niyw bruwm swiyp gud [kliyn], bot wol bruwm nwow de kana dem/

"(The) new broom sweeps well (clean) but old brooms know the corners."

An old mate knows a person's ways better than a new one and can hence avoid friction better.

A new friend gets all the attention while older friends

are being neglected although they are more trustworthy.

123. /kichin towel ton tyebl klwot/

"Kitchen towel turns table cloth."

One who puts on airs above his station; a nobody who pretends

to be somebody. Said about someone who acquired wealth or

position and is mean to those beneath him/her.

124. /neva siy kom siy/

"Never see come see."

Has never seen money, but wants to have the good life.

Someone who has been poor before, when he is suddenly

affluent, he doesnt know how to spend the money.

125. /kom siy miy and kom liv wid miy a two difren ting/

"Come to see me and come to live with me are two different things."

One cannot tell what someone is really like from outward

appearances; one must encounter someone closely to get to know

the person well. 
126. /wa fal from di hed mos drop pon di shoulda/

"What falls over the head must drop upon the shoulder."

Children usually inherit the parents' possessions and idiosincracies.

Sharing should be encouraged; the benefactor will be rewarded.

127. /iyziy skwiyz mek na rayot/

"Easy squeeze makes no riot."

There is no need for a confrontation. Well applied pressure does not hurt and will get results.

128. /avi, avi, avi, na wanti; wanti, wanti, wanti, kyaan get it/ "Have it, have it, have it, does not want it; want it, want it, want it, can't get it."

Those who have something don't want it; those who want it, cannot have it. People don't appreciate what they have.

129. /wen piypl na layk yuw, dem giy yuw baskit fi kary wata/ "When people don't like you, they give you a basket to carry water." When people don't like you, they make your life impossible by giving you difficult tasks.

130. /evriy eg im av afi bi in di red/ "Every egg she has must be in the yoke."

Someone needs to be the center of attention constantly. Someone intends to be fully involved in something to become /hed kuk an bokl washa/.

131. /an so miy bay it an so miy sel it/ "And so I buy it and so I sell it." I am telling the truth; I haven't changed the story.

132. /if yuw yon and yuw na ded yu mos ton wol/ "If you are young and you haven't died you must turn old." You must not look down on an old person because eventually you will get old too.

133. /wen yu nyeba biyd kyach faya, yuw afi trwo wata pon yu biyd/ "When your neighbor's beard catches fire, you have to throw water upon yours."

You must learn to handle calamities from other people's experience.

134. /ay wudin tros im from miy ay tu miy nwozl "I wouldn't trust him from may eye to my nose." I wouldn't trust him at all. 
135. /miy no tros no shado afta daak/

"I don't trust any shadow after dark."

Do not trust someone you are not sure about.

136. /wen yuw de pan de ars, yuw mayt az wel rayd im/

"When you are upon the horse, you might as well ride him."

Once you are in a situation, you might as well weather it.

You must see something through, even if you did not choose to

look for a particular situation.

137. /wen yuw get ina de kanuw, yuw mayt az wel pagl it/

"When you get inside a canoe, you might as well paddle it."

You must face new situations.

Cf. S "Si estás en el baile, tienes que bailar."

138. /yuw wown siy wowl bwon/

"You won't see old bone."

You will not live to be old because you're living too fast.

139. /tuw masta fi wan ows/

"Two masters for one house."

You can't have two many people giving orders.

Cf. SE. "Too many cooks spoil the broth."

140. /wen man ded, gras grwo a im dwo/

"When a man dies, grass grows at (in front of) his door."

An issue loses its impact if it is not dealt with promptly.

When a person leaves, no one else will care for his things.

Cf. SE. "When the cat is away, the mice will play."

141. /a wown iyvin swe fi miy as, it bihayn miy/

"I won't even swear for my ass, because it is behind me."

One cannot assume responsibility for anybody else.

142. /wat iz fon tu yuw iz det fi miy/

"What is fun for you, is death for me."

What might be amusing to you may displease me greatly.

143. /had iyz pikni wak tuw taym/

"A hard-ears (stubborn) child walks two times."

If a child doesn't obey, he/she has to do the same thing

twice. Being a stubborn person creates problems. 
144. /yuw kyaan mek blod owta twon/

"You can't make blood out of stone."

You must learn to live within your means.

145. /im av de hangl and yuw av de blyed/

"He has the handle and you have the blade."

If you are at a disadvantage, exercise caution.

146. /wen yuw an ina layon mowt, yuw afi tek taym pul it owt/

"When your hand is in a lion's mouth, you must take your time to pull it out." If you are in a vulnerable position, don't act hastily or aggressively. Don't intimidate your superior.

147. /yuw kyann ekspek fi sliyp saaf, if yuw spred yuw bed pon stwon/

"You cannot expect to sleep softly, if you spread (make)

your bed upon a stone."

We are the perpetrators of our own misery; we are responsible

for our own actions.

148. /yuw av fi kriyp bifo yuw waak/

"You have to creep before you walk."

One has to go slowly in life and not wish for everything to happen at once.

149. /miy hay a miy markit, miy luk ina eniy koko-baskit/

"My eye is my market, I can look in any coco-basket."

You can't prevent anybody from looking.

An individual is free to do as he pleases.

150. /bifo gud fud wyes, mek beliy bos/

"Before good food goes to waste, make belly burst (overeat)."

It is better to be uncomfortable from overeating than letting good food go to waste.

151. /im dres tu pus bak fut/

"He is dressed to puss back foot."

He is overdressed for the occasion.

152. Ina put yuw hat haya dan yuw kyan riych it/

"Don't put your hat higher than you can reach it."

Don't be unrealistic about your goals.

153. /miy neva tel im se im ay red/

"I didn't tell him his eye was red."

Said at the slightest offense, when there is no provocation. 
154. /miy no "av bluw buwt fi go a kwot/

"I don't have blue boots to go to court."

Said by a person who wishes to avoid legal confrontation.

155. /yuw av bluw buwt fi gow a kwot/

"You have blue boots to go to court."

You will get into serious trouble, into a hot spot.

156. /im kyan tiyf milk owta kafiy/

"He can thief (steal) milk out of coffee."

He will steal anything.

157. /im tiyf yu andegyament widowt tekin of yu trowziz/

"He can thief (steal) your undergarment without taking off your trousers."

He will steal anything, and he is an expert at stealing.

158. /im likl bot im talwa/

"He is little but he is stalwart."

He is young but smart or strong for his age.

159. /de mwo yuw luk, de les yuw siy/

"The more you look, the less you see."

A snoopy person will gain little information, because people

will be more secretive with someone nosy.

160. /kal miy a laya bot dwon kaal miy a tiyf/

"Call me a liar but don't call me a thief."

To tell someone he is a thief is the worst insult; it also

implies that a person has been cheating as well.

161. /im miyn layk a starapel triy/

"He is as mean as a star-apple tree."

As the fruits of the star-apple never fall to the ground, so

a stingy person does not wish to let go of his possessions.

162. /yuw sit on a diego bench/

"You sit (straddle) on a diego (Spaniard) bench."

You are a double-faced person; a hypocrite.

163. /aks miy egen, ay spit in yuw fyes/

"Ask me again, and I will spit in your face."

If you are too inquisitive, you will pay for it. 
164. /no giy we yu as an shit truw yuw ribz/

"Don't give away your arse and defecate through your ribs."

Don't allow your fear or shame to save your friends from embarrasment.

Don't give away something you can still use, just to look

good. Don't be too considerate to your own disadvantage.

165. /hu shit a rwod sayd no rimemba it, bot huw fut get in de neva faget it/

"Who defecates on the road side doesn't remember it, but whose

foot steps on it, never forgets it."

The person who creates a problem soon forgets it, but he who

suffers the consequences will not easily forget.

166. /yuw gowing tu pye fi rwoast an bwayl/

"You are going to pay for roast and boil."

You are going to be punished for sure.

167. /spiyk wen yuw spwokin, ansa wen yuw kaal/

"Speak when you are spoken to, answer when you are called."

Mind your own business.

168. /tek yu ayz an luk bot dwon toch/

"Take your eyes and look but don't touch."

Mind your own business (said especially to children).

169. Ino dash we yu tik bifo yu don kras/

"Don't discard (throw away) your stick before you are done

crossing (the river)."

/dwown bon yu brij bihayn yuw/

"Don't burn your bridges behind you."

Don't part with friendships and things too hastily; you may wish to have them later in life.

170. /yuw gowing nyam dray bred an sol/

"You are going to eat dry bread and salt."

You are spending too much, hence you are going to go through hard times later.

171. /stryenja no nwo bak dwo/

"Strangers don't know the back door."

Don't turn your back against your own kin -they know you well.

Someone who is not familiar with a person or a place will be clumsy. 
172. /tudye fi miy, tumara fi yuw/

"Today for me, tomorrow for you."

Each person has its day of reckoning; no wrongdoing goes unpunished.

173. /wa stye tuw long serv neda man/

"What stays too long serves another man."

If you own something, use it; if you neglect to use it, someone else will.

174. /wa yuw no nwo olda dan yuw/

"What you don't know is older than you."

Older people know more than the young from experience.

175. /waan aal, yuw luwz al/

"When you want all, you will lose all."

A warning to someone who is greedy.

176. /wuman a heviy lwod wen sachudye maanin kom/

"Woman (is) a heavy load when Saturday morning comes." A woman implies a "heavy load" (i.e. great responsibility in terms of expenses) for a man; he gives his woman his money on Friday (pay day), thus she is quite costly.

177. /yuw luk pon miy layk washa wuman luk pon ditiy bongl pon mondye maaning/

"You look upon me like a washer woman looks upon a dirty bundle (of clothes) on Monday morning."

To give someone an unfriendly, disdainful look.

178. /im kyann mash ants/

"He cannot smash an ant."

He is so meek-looking that you cannot conceive of his damaging anything or anybody.

179. /im dwown nwo "b" from bulfut/ or

lim dwown nwo im iyez from im as/

"He cannot distinguish a "b" from a bull's foot."

"He cannot tell his ears from his ass (i.e. buttocks)"

$\mathrm{He}$ is completely ignorant.

180. /emtiy bag kyann tan op/

"An empty bag cannot stand."

Words that are empty, cannot be effective.

A hungry person cannot work and will collapse. 
181. /emtiy bag kyaan ton op, bot ful bag kyaan ben/

"An empty bag cannot stand, but a full bag cannot bend."

Although a starved person may collapse, one who is too

satisfied will not be able to perform his tasks efficiently.

182. /layk bench an batiy/

"Like bench and bati (also spelled "batty')."

A very close relationship.

Cf. SE. "Like hands and gloves."

183. /wid blod ina im ay/

"With blood in my eye."

I will do something with determination; I am very upset.

184. /ful beliy tel emptiy beliy kiyp haat/

"A full belly tells a hungry belly to keep heart."

Someone who offers assistance, but does so only with words.

185. /bak a grown, moniy a han/

"Back on the ground, money in hand."

Said about prostitutes who make a fast dollar.

186. /blod tika dan wata/

"Blood is thicker than water."

One is closer to one's relatives than to strangers.

187. /evriy dye de bokit go a wel, wan dye de botom go a drop/

"Every day the bucket goes to the well, one day the bottom is

going to drop (fall out)."

Those who engage in wrong doing habitually will some day pay

the consequences.

Cf. "Tanto va el cántaro al agua que al final se rompe."

188. /huw de kap fit, mek im wer it/

"Whom the cap fits, let him wear it."

Whoever is guitly must assume responsibility.

189. /kap no fit yuw, yuw no tek it op/

"If the cap doesn't fit you, don't take it up."

If the accusations are mistaken, why react?

190. /kyariy gow, kyariy kom/ or /kyariy gow, bring kom/

"Taking to and carrying back," or "Taking to and bringing back."

Said about someone who is a gossiper and takes information back and forth. 
191. /ed kuk an bokl washa/

"Head cook and bottle washer."

Said about a person who becomes very involved in an activity.

192. /wod iz win bot blwow iz ankayn/

"The word is wind, but blows are unkind."

Curses do not break any bones.

Don't pay attention to the mean things said by an adversary.

193. /wen wan doo shot, nada wan wopin/

"When one door is shut, another one opens."

Be corageous and don't succumb to hopelessness, because there may be a solution to adversity.

Cf. "Every cloud has a silver lining."

194. /wa ay no siy, haat no liyp/

"What the eyes don't see, the heart does not leap for."

You should not be alarmed by a situation you did not witness.

Cf. S. "Ojos que no ven, corazón que no siente."

195. /jast se fe/

"Just say 'fe'."

Among children it expresses a challenge to fight, i.e. "I dare you."

Said by a mother to her children, it means "shut up," or else

face the consequences.

196. lif yuw nwo sombodiy a dye taym, yuw no afi shayn layt ina im fyes fi nwo im a nayt/ or /in a daaknis/

"If you know somebody at day time, you don't have to shine a light on his face to know him at night." (or in darkness).

You don't have to put too much effort into accomplishing a task you are already familiar with.

197. /hyes meks wyes/

"Haste makes waste."

Activities performed in time are accomplished with a higher degree of efficiency. Hurrying over something may create problems.

Cf. SE. "Haste makes waste."

198. /giy yuw jacket fi wer/

"Give your jacket to wear."

Said about a woman who names someone the father of her child, when he is really not. 
199. /hel an powda 'ows/

"Hell and powder house."

/hiy/shiy gow tu dead doo an kom bak/

"He/she went to death's door and came back."

Said about someone who has gone through a great deal of

difficulties. Also used as the result of an obeah curse.

Cf. SE. "She went through hell and back."

200. /de wan u laaf las, laaf bes/

"The one who laughs last, laughs best."

He who has the last word is usually better off.

Cf. S. "El que ríe (de) último, ríe mejor."

201. /spil milk kyaan be gada/

"Spilt milk cannot be gathered."

Don't worry about what has happened, since the past cannot be undone.

Cf. SE. "Don't cry over spilled milk."

202. /yuw mowt mos a jayn choch kos im bak/

"Your mouth must have joined a church (when you) cursed him back."

Said about someone who does not answer back someone's unleashed

tirade with the same tone of offense, but is instead quite soft spoken.

203. /moniy no grwo pon triy/

"Money does not grow on trees."

Wealth is the result of hard work, thus do not ask for money

since it is a scarce commodity, not easily made.

204. /miy nyevel string beriy de/ or /a de miy nyevel string de/ or

/a de miy nyevel string beriy/

"My navel-string (umbilical cord) is buried there."

I am from there. I am a true born "Costa Rican", for example.

205. /yuw a flay pas yuw nes/

"You are flying past your nest."

You are very rude, daring, disrespectful, impertinent.

206. Iput yuw pot pon faya if yu bay dity fay, bot if not no put yu pot pon faya/

"Put your pot on the fire if you buy " 35 ", but if not, don't put your pot on the fire."

Don't get your hopes up unless you bought No. 35 in the lottery, because that is the number that is going to win. 
207. /ketel a kaal pot blak/

"The kettle is calling the pot black."

Someone with many faults is criticizing someone else who is

not deserving of such harsh criticism. "Look who is talking!"

Cf. SE. "The pot calling the kettle black."

208. /no beta barel, no beta hering/

"No better barrel, no better herring."

The child follows the wrongdoings of his/her parents.

209. /no kas perl bifo swayn/

"Don't cast pearls before swine."

Don't waste your efforts among those who cannot appreciate them.

Cf. SE. "Don't throw pearls to the swine."

210. /mayn mosi drop from de skay/

"Mine (My child) must have dropped (fallen) from the sky."

Ironic expression said by a woman in reference to her delivery

(i.e. as if the birth had been without pain), when another

woman mentions the pain she endured during her delivery.

211. /somtin ina somtin/

"Something is in something."

Something is wrong with his behavior, there must be an

ulterior motive behind it.

Cf. S. "Por algo es!"

212. /ruwmful, 'aalful, yuw kyaan get a spuwnful/

"Roomfull, hallfull, you cannot get a spoonfull."

Although there is an abundance of something, you can't get any for yourself.

Someone who "does not see the forest for the trees," he/she is concerned

about the details and fails to capture the importance of the whole picture.

213. /yuw siy tudye, yuw no siy tumara/

"You see today, you don't see tomorrow."

Make the most of the present, because the future is uncertain.

214. /no dra miy tong/

"Don't pull my tongue."

A warning said by the speaker to the interlocutor that he/she will not tolerate any further annoyance, because he/she is at the end of his/her tether. 
215. /wata mwo dan flowa/

"Water is more than flour."

The speaker is experiencing financial hardship and cannot make ends meet.

216. /wata an ayl neva miks/

"Water and oil never mix."

Said about two people who do not agree with each other.

217. /im a step layk pus pon 'at brik/

"He is stepping like a cat on hot briks."

Said about a person who is haughty and considers himself special.

218. /faya de a maws tyel, im tink a kuwl briyz/

"When there is fire at a mouse's tail, it thinks it is a cool breeze."

You mistake evil for good; you think a person is wonderful

although he/she is really a good for nothing.

219. /wan rotin tomyeto (apel, pye) wil payl de hwol gruwp/

"One rotten tomato (apple, pear) will spoil the whole gruwp."

The wrong company may spoil the good customs of a child.

220. /de mwo yuw liv, iz de mwo yuw leen/

"The longer you live, the more you learn."

You become wiser with experience.

221. /it tek a tiyf tu kyach a tiyf/

"It takes a thief to catch a thief."

It takes one to know one.

222. /gii im rwop, im wi hang imself/

"Give him rope, he will hang himself."

Let an enemy fall in his own trap instead of fighting against him yourself.

223. /drank man an children taak de truwt/

"A drunken man and the children tell the truth."

A person without inhibitions will be truthful.

Cf. S. "Los borrachos y los niños dicen la verdad."

224. /we de triy faal, de shal it lye/

"Where the tree falls, there shall it lay."

Don't try to change something when it is not productive to do so.

Cf. SE. "Where the axe fells the tree, there it shall lie."

Cf. SE. "Let sleeping dogs lie." 
225. /tan an siy no spayl dans/

"To stand and see doesn't spoil the dance."

To stand by and watch has no effect.

226. /if yuw no av guw fi se, no se bad/

"If you don't have anything good to say, don't say bad (things)."

It is better to keep your mouth shut than spread ill gossip.

227. /dwon mek yu lef han nwo wa yuw rayt han nwo/

"Don't let your left hand know what your right hand knows."

Keep your secrets to yourself.

228. /tuw hed beta dan wan, iyvin if wan a kokohed/

"Two heads are better than one, even if one is a coco-head."

It is better to work in a group than face things alone.

Cf. SE. "Two heads are better than one."

229. /if iez no ie, aas gowin fiyl/

"If (your) ears don't hear, your ass is going to feel it."

If you don't pay attention, you will eventually feel the effects of what has been said.

230. /gii yuw an inch, yu tek a yaad/

"Give you an inch, you take a yard."

If you are given some leeway to do things, don't become over demanding.

231. /wa no kil yuw wi fatin yuw/

"What doesn't kill you will fatten you."

What will do you no harm will probably help you.

Cf. S. "Lo que no mata engorda."

232. /lov don, fon don/

"Love done, fun done."

When love is over, the fun is over too.

233. /self pryez iz no pryez/

"Self praise is no praise."

If praise is deserved, you will get it, but praising yourself

for something is unwarranted.

234. /siy an blayn, hiyr an def/

"See and blind, hear and deaf."

Don't talk about everything you see or hear. 
235. /syem tin wa swiyt mowt sik beliy/

"The same thing that is sweet to the mouth might sicken the belly (stomach)." Not everything that you eat will agree with you.

Not everything that you do will ultimately be good for you.

236. /stadiyryeshon biyt edyukyeshon/

"Studying a situation beats (is better than) education."

/kaman sens beta dan edyukyeshon/

"Common sense is better than education."

Common sense applied to a situation usually produces a more

sensible solution than that taken as the result of education.

237. /tong an tiyt av fi miyt/

"Tongue and teeth have to meet."

In a discussion, the contenders (e.g. husband and wife) have

to work together towards understanding each other, though

their opinions may clash.

It is natural for a couple to argue.

238. /if im se a no im, a im; if im se a im, a no im/

"If he says it wasn't him, it was; if he says it was him, it wasn't."

You must interpret what people say, knowing full well that they might be hiding the truth.

239. /tuw moch ari get de tumara; tek taym get de tudye/

"Too much hurry, get there tomorrow; take time, get there today."

It is better to take the time to do things properly.

240. /pompkin neva bye wata/

"Pumpkins and watermelons don't grow on the same vine."

Don't expect the impossible.

Cf. S. "No le pidas peras al olmo."

241. /wen byeby waan kray yuw ongliy afi luk pan im i kray/

"When baby wants to cry you only have to look at him and he will cry."

The same as the baby who is looking for a pretext to cry, if you really wish to do something you will achieve it.

242. /ful beliy tel emtiy beliy, kiyp 'aat brada/

"Full belly (stomach) tells empty belly (stomach), 'Keep heart brother!'."

Cynic remark to express lack of empathy; someone who is well

off encourages someone who is not, without really

understanding the other person's suffering. 
243. /disya taym no tan layk bifwo taym/

"This time (the present) is not like (doesn't stand like) the past." Times are changing.

244. /no chyenj blak daag fi monkiy/ "Don't change a black dog for a monkey."

Don't change the devil for a witch; don't change something bad for something even worse.

245. /we fi apen afi apen/

"What has to happen will happen."

The future will take its course.

246. /syek a mowt fish get kach/

"For the sake of its mouth the fish gets caught."

Mind what you say.

Cf. S. "El pez muere por su boca."

247. /likl achit faal big triy/

"A little hatchet can fell a big tree."

Some little detail can destroy a great enterprise.

248. /siknis kom gyalp pan aasbak, bot im tek im tuw fuwt fi waak we/ "Sickness comes galloping on horseback, but walks away on two feet (it takes two feet to walk away)."

Something bad, upsetting, can come fast, but it takes forever to go away.

249. /evriy dye devl elp tiyf, wan dye gad de elp wachman/

"Every day the devil helps the thief, but one day God helps the watchman." You can't 'get away with murder' every day.

250. Ino kya ow man se im bad, man kyaan bada dan det/

"No matter (don't care) how man says he is bad, man cannot be worse ('badder' $=$ /bad $+\mathrm{a} /$ ) than death."

No matter how evil a man may be, death is more than his match.

251. /wen sombodi ded, dem ded fi truw/

"When someone is dead, he is really dead."

When someone dies, he is really gone.

252. /kuk op yuw fat in jesta pat, bot no trwo we yuw wol bon pan/ "Cook your fat in a digester pot, but don't throw away your old burned pan." Don't give up your old friends and possessions, just because you have acquired new ones. 
253. /'at niygl bon tred/

"Hot needle burns the thread."

Even your own body can conceivably go against you.

254. /no beta erin, no beta baril/

"No better herring, no better barrel."

One is not better than the other.

255. /shaat paas draa blod, lan paas draa swet/

"A short-cut might draw blood; the longer route will draw only sweat."

It's better to do things the right way even if it takes longer.

256. /if yuw a bul baka, miy a dopi kangkara/

"If (you think) you (can) ride a bull, I (can believe myself)

a conqueror (of ghosts)."

Even if you think you are powerful (because you can ride a bull), I am even stronger; i.e. I can conquer ghosts.

257. /im a faam fuwl fi kech wayz/

"He is pretending to be a fool to outsmart (catch) the wise."

Act with a low profile to get an idea of a situation.

The reason why proverbs function as effective communicative devices is because they set up the hearer to draw practical inferences from listening to one or more key propositions embedded in a cultural model with known entailments. The metaphorical form allows these propositions and their behavioral entailments to be focused sharply because the proverb connects them tightly. It is apparent that interlocutors go beyond the utterance itself to comprehend the meaning: speaker and hearer must share a common background of cultural knowledge and a compact economy of reasoning.

Proverbs about human temperament frequently draw from the domain of animals (as apparent in the lists provided). In that domain, we understand nonhumans in terms of humans; i.e. animal characteristics are interpreted metaphorically in terms of human characteristics. Some common propositions that appear in schemas for animals in the Western world are:

-pigs are dirty, messy and rude

-lions are courageous and noble

-foxes are clever

-dogs are loyal, dependable and dependent

-cats are fickle and independent

-wolves are cruel and murderous

-gorillas are aggressive and violent 
Our understading of what these animals are like is metaphorical. They belong to a cultural model, in this case to that of the Afro-Antilleans. For them, the dog is seen as the poor man, the monkey as the senseless man, the same as in Anacy stories where Brother Nancy, the spider, is crafty. It is apparent that proverbs undergo remolding under the influence of native conditions. They are usually applied to poverty, hunger, injury, want. They are almost never applied to love, heroism, beauty, and women are usually belittled. They express a sense of wrong doing, the nursing of injuries (real or imagined) suffered by the weaker folk, inflected on them by those whom they couldn't avenge themselves from, because they were much weaker.

As touched upon above, when it comes to usage, proverbs have an important feature in common: they deal with social situations which may be difficult to handle in a direct way; they may also deal with strained relations, or with ambiguous conceptual categories. In that sense, proverbs may function to restore equilibrium in situations of classificatory uncertainty (for instance, in the case of taboo subjects). Thus topics which would not normally be addressed in ordinary discourse get treated by circumlocution, via metaphorical ambiguity, which in the end might serve to strengthen the discreteness of the categories.

If the indirect treatment of a topic provides multiple meanings and the social context is far from being optional but rather constitutes primary data, then it is immediately apparent that the methodology employed in the collection of proverbs becomes essential. Arewa and Dundes have offered some guidelines:

One needs to ask not only for the proverbs, and for what counts as a proverb, but also for information as to the other components of the situations in which proverbs are used. What are the rules governing who can use proverbs and to whom? Upon what occasions? In what places? With what other persons present or absent? Using what channel? (e.g. speech, drumming, etc.)? Do restrictions or prescriptions as to the use of proverbs or a proverb have to do with particular topic [sic]? with the specific relationship between speaker and addressee? What exactly are the contributing contextual factors which make the use of proverbs, or of a particular proverb, possible or not possible, appropriate or inappropriate? (1964: 71).

\section{Conclusion}

The present findings support the importance of the discourse context in determining the meaning of proverbs. The dual focus on the proverb text and the social situation of the usage contests the a priori assumption that the proverb consists of the text alone. Moreover, cultural models are revealed through proverbs. It is apparent that proverbs make use of an imaginative mechanism, the metaphor, and that they are not only the result of imagination, but they are motivated by concrete world objects, such as humans, animals, plants, complex and natural objects. Finally, linguistic evidence is a precise guide to the structure of such cultural models.

What can this description of pragmatics of a single genre in a single language tell us about the broader issues which are raised by investigations of the use of language in society? 
Proverb performance helps gain important insights into the pragmatics of social interactions. They are extremely subtle indexes of the social and conversational roles that obtain between participants. However, generalizations must wait for similar genres research in other speech communities. Eventually, these findings will broaden our understanding of the nature of speech events and their roles in social life.

\section{Notes}

1. The Anancy stories of the Afro-Antillean tradition were brought from Africa by the slaves. These fables were named for their hero Brother Nancy, the spider, who like other animals in the stories assumes human characteristics. /brada nansi/ is a trickster who steals, cheats, deceives his 'friends' and goes against all of society's ethical codes. He is usually deservedly punished.

2. As people mature and frequently live the experience the proverbs forecast, they repeat to their children what they heard from their elders when they were growing up-in much the same way as adults incorporate in their lifestyle many of their parents' customs, although they may have considered such habits with derision during their youth. Thus one often hears proverbs introduced by the frame, "As your grandma used to say..."

3. The authors would like to express their great appreciation to the late Eugenie Perry, and to Lurline Williams and Marcia Reid for their valuable contribution.

4. Since LC is primarily an oral language (except for some known attempts at writing poems and narratives using Standard English symbols), the LC proverbs here collected are conveyed in a broad phonemic transcription, adapted from The Dictionary of Jamaican English by F.G. Cassidy and R.B. Le Page. This transcription should make the proverbs accesible to all readers, even to those without formal linguistic training. The presentation format adopted is as follows:

1) No particular order is implied by the number which appears on the left of the saying; it is simply meant to facilitate references to it.

2) The proverb is transcribed as heard in oral exchanges.

3) An almost literal translation into Standard English (SE) is provided.

4) An explanation of its meaning, and sometimes a SE version as well as a Spanish (S) equivalent follows. However, this practice is by no means meant to be exhaustively used for all examples.

For all practical purposes, in an effort to accommodate word processor characters rather than phonetic symbols, the following conventions have been used in the phonemic transcription:

To convey the sound of [ $]$ ], /sh/ will be used;

to convey the sound of $[\mathrm{t} f], / \mathrm{ch} /$ will be used;

to convey the sound of [n],/ng/ will be used;

to convey a long vowel [i:], /iy/ will be used;

to convey the semivowel[w], /uw/ will be used.

5. The fact that proverbs are difficult to recall from memory without an eliciting context or situation raises questions about the form in which they are stored in memory. They are probably tied to cultural knowledge about types of situations or action-scenarios. This knowledge is activated, generated, or assembled in the course of understanding specific events. 


\section{Bibliografía}

Arewa, E. Ojo y Alan Dundes. 1964. "Proverbs and the Ethnography of Communication”. En: John J. Gumperz y Dell Hymes (eds.), (66): 70-85.

Briggs, C. L. 1985. "The Pragmatics of Proverb Performance in New Mexican Spanish". American Anthropologist. (87): 793-810.

Cassidy F.G. y R.B. Le Page. 1967. Dictionary of Jamaican English. Cambridge: Cambridge University Press.

Edmonson, Munro S. (ed.). 1973. Ethnolinguistic Studies. The Hague: Mouton.

Gossen, Gary H. 1973. "Chamula Tzotzil Proverbs: Neither Fish nor Fowl. Meanining in Mayan Languages”. En: Munro S. Edmonson (ed.), 205-34.

Lakoff, George y Mark, Johnson. 1980. Metaphor we live by. Chicago: University of Chicago Press.

Taylor, Archer. 1931. The Proverb. Cambrige: Harvard University Press. 